\title{
Bone marrow cell transplantation efficiently repairs tendon and ligament injuries
}

\author{
Taketoshi Kushida * and Hirokazu lida \\ Department of Orthopaedic Surgery, Kansai Medical University, Hirakata, Japan \\ *Correspondence: kushidat@hirakata.kmu.ac.jp \\ Edited by: \\ Kequan Guo, Beijing Anzhen Hospital affiliated to Captial Medical University, China \\ Reviewed by: \\ Jeroen JJP Van Den Beucken, Radboud University Nijmegen Medical Centre, Netherlands \\ Vimal Kishor Singh, Defence Research and Development Organisation, India
}

Keywords: bone marrow cell transplantation, tendon, ligament, TGF- $\beta$, fibroblast

\section{INTRODUCTION}

Growth factors such as transforming growth factor- $\beta$ (TGF- $\beta$ ), vascular endothelial growth factor (VEGF), insulin-like growth factor-1 (IGF-1), platelet-derived growth factor (PDGF), and basic fibroblast growth factor (bFGF) have been associated with the tendon healing process (Molloy et al., 2003; Zhang et al., 2003; Halper, 2014). Among these growth factors, TGF$\beta 1$ plays a key role during the various tissue repair stages and is secreted not only by fibroblasts differentiated from mesenchymal stem cells (MSCs), but also by several types of cells that differentiate from hematopoietic stem cells (HSCs; Sporn et al., 1986).

In this review, the role of TGF- $\beta$ and MSC-derived fibroblasts in tendon and ligament tissue repair is described. Furthermore, the potential application of bone marrow cell transplantation (BMCT) as a novel method for treating tendon and ligament injuries is also discussed.

\section{HEALING PROCESS}

Human tendon healing process is classified into five phases as follows: immediate post injury phase, inflammatory phase, proliferation phase, reparative phase, and remodeling phase (Molloy et al., 2003). Tissue repair depends on both intrinsic and extrinsic processes. Intrinsic healing occurs within the tendon itself as a result of the activity of intrinsic fibroblasts and an increased intratendinous blood supply from the synovium and osseous insertion (Deie et al., 1995; Koga et al., 2007). Extrinsic factors that influence tissue repair include the availability of proteins originating from peripheral fibroblasts, plasma, inflammatory cells, and extratendinous vascular invasion (Lee et al., 1998; Zhang et al., 2003).

\section{FIBLOBLASTS AND COLLAGEN FIBERS IN TISSUE REPAIR}

During the inflammatory phase, fibroblasts located within the tendon proliferate and circulatory fibroblasts migrate into the injured tissue site. The fibroblasts then synthesize new extracellular matrix proteins that predominantly consist of collagens and glycosaminoglycans (Molloy et al., 2003). The tendon is primarily made up of type-I collagen along with small amounts of other collagens such as typeIII collagen. Type-I collagen is a mature form of collagen and is mainly responsible for the mechanical strength of the tendon. On the other hand, type-III collagen, which is thinner and more extensible than type-I collagen, is not a major collagen in normal tendon. However, type-III collagen is required during the earliest stage of tendon healing because it can rapidly cross link and stabilize the precarious repair site (Liu et al., 1995; Eriksen et al., 2002).

\section{GROWTH FACTORS}

As mentioned previously, growth factors are essential during the various stages of the tendon healing process (Molloy et al., 2003; Zhang et al., 2003; Halper, 2014). Among these growth factors, TGF- $\beta$ and VEGF are important for initiating tissue repair (Molloy et al., 2003; Mienaltowski and Birk, 2014). Furthermore, TGF- $\beta$ can enhance the production of VEGF (Anitua et al., 2005; Wang et al., 2005,
2008). TGF- $\beta$ regulates various biological processes including cell proliferation, migration, differentiation, apoptosis, and extracellular matrix deposition (Molloy et al., 2003). In particular, TGF- $\beta 1$ accelerates the proliferation and matrix synthesis of ligament fibroblasts (Schmidt et al., 1995; Marui et al., 1997; Scherping et al., 1997). In addition, TGF- $\beta$ modulates proteoglycan deposition and stimulates the production of collagens by fibroblasts (Fu et al., 2005).

VEGF is also a powerful stimulator of angiogenesis and is especially important during the proliferative and remodeling phases (Molloy et al., 2003). Zhang et al. reported that the injection of exogenous VEGF in the injured site can significantly improve tensile strength of the rat Achilles tendon by stimulating growth factor production, which improves fibroblast proliferation (Zhang et al., 2003).

\section{ROLE OF BONE MARROW CELLS IN TISSUE REPAIR}

Recently, platelet-rich therapies that use a multitude of growth factors have been reported to good clinical outcomes for soft tissue injuries (Moraes et al., 2014). However, Kiapour et al stated in their review that the platelet-rich therapies have challenges associated with the short life span of these bio-active agents and the limited treatment efficacy. Furthermore. Kiapour et al stated that platelet-rich therapies required safe and reproducible systems that allow sustained delivery of growth factors to the injury site are essential (Kiapour and Murray, 2014). 
Bone marrow cells (BMCs) consist of MSCs and HSCs, which can further differentiate into various cell types that secrete growth factors (Sporn et al., 1986; Baylink et al., 1993). For example, HSCs have the capacity to differentiate into growth-factor-secreting hematolymphoid cells such as lymphocytes, macrophages, granulocytes, eosinophils, erythroblasts, erythrocytes, and megakaryocytes and these cells secrete tissue repair cytokines such as TGF- $\beta 1$ (Sporn et al., 1986). On the other hand, MSCs have the capacity to differentiate into several types of cells including osteocytes, chondrocytes, myotubes, stromal cells, fibroblasts, and adipocytes (Caplan, 2009; Wang et al., 2013). In particular, inflammatory cytokines such as IL- $1 \beta$ induce differentiation of MSCs into osteoblasts and promote mineralizing of soft tissues (Ferreira et al., 2013). MSCs themselves produce growth factors and anti-inflammatory cytokines (Le Blanc and Ringdén, 2006; Wang et al., 2008). Furthermore, MSCs differentiate into cells that participate in tissue repair and secrete growth factors and cytokines (Zantop et al., 2006; Chong et al., 2007; Ju et al., 2008). Undifferentiated MSCs produce growth factors and cytokines that promote the expansion and differentiation of HSCs and modify the response of inflammatory immune cells (Le Blanc and Ringdén, 2006).

\section{BMCT FOR TREATING TENDON RUPTURE}

The effectiveness of MSC transplantation is due to the differentiation of MSCs into cells that participate in tissue repair and also due to the release of paracrine factors such as growth factors and cytokines by the transplanted cells (Wang et al., 2008). Previous studies show that injecting MSCs at injury sites can accelerate Achilles tendon healing in animal models (Zantop et al., 2006; Chong et al., 2007; Hou et al., 2009). Chong et al have reported that bone marrow-derived MSCs influence early tendon healing in rabbits (Chong et al., 2007). Zantop et al have reported that extracellular matrix scaffolds are repopulated by bone marrow-derived cells in a mouse model of Achilles tendon reconstruction (Zantop et al., 2006). Hou et al. have characterized the effects of TGF- $\beta 1$ and $V E G F_{165}$ gene transfer on Achilles tendon healing (Hou et al., 2009).

Recently, we characterized the effects of injecting whole BMCs, which consist of both MSCs and HSCs, on tendon healing in a rat model of Achilles tendon rupture and evaluated the effects of growth factors on the early stages of healing (Okamoto et al., 2010). We showed that the levels of TGF- $\beta$ and VEGF in tendons treated with BMCs were higher than those in tendons treated with MSCs. Thus, the BMC-treated group showed a rapid increase in types-I and III collagen and faster recovery of the ultimate failure load.

\section{BMCT FOR TREATING ANTERIOR CURUCIATE LIGANENT PARTIAL RUPUTURE}

Spontaneous regeneration of anterior cruciate ligament (ACL) is impeded by the lack of soft tissue around it. However, partially ruptured ACL can regenerate with growth factor administration and after cell transplantation. Intra-articular transplantation therapies using MSCs have been used for treating torn ACLs (Agung et al., 2006; Kanaya et al., 2007). Kanaya et al showed that the injected MSCs produced growth factors such as PDGF, bFGF, and TGF- $\beta$, which can activate the native ACL cells. The authors proposed that the native ACL cells may have proliferated and migrated into the injured area of the ACL. Furthermore, Agung et al have characterized the mobilization of bone marrow-derived MSCs into the injured tissues after intra-articular injection and their role in tissue regeneration (Agung et al., 2006). Taken together, these studies indicate that intra-articular transplantation therapies using MSCs have excellent outcomes for the regeneration of a transected ACL.

Recently, we showed that partially transected rodent ACL can be repaired by injection of BMCs or cultured MSCs into the articular cavity at 1 week after transection (Oe et al., 2011). The rat ACLs of the BMC and MSC groups after 4 weeks of treatment appeared almost normal histologically, and the tensile strength of the ACLs of the BMC group reached near normal levels biomechanically. Furthermore, immunostaining for type-I collagen showed that the number of nuclei in the BMC group was significantly higher than that in the MSC group or the saline group. The levels of TGF- $\beta 1$ in the ACL tissue and knee joint fluid in the BMC group were significantly higher than that of the saline group at 4 weeks. In conclusion, intra-articular bone marrow transplantation using fresh whole BMCs is an effective treatment for ACL partial rupture (Figure 1).

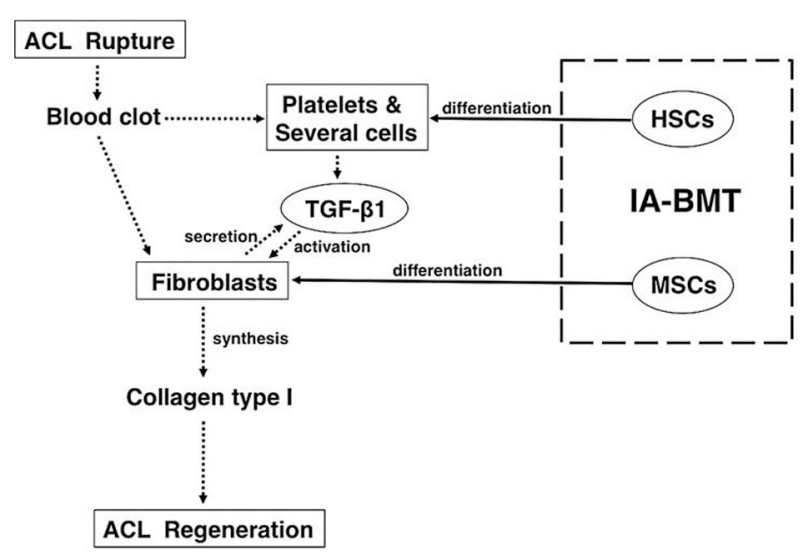

FIGURE 1 | Mechanisms underlying the treatment of anterior cruciate ligament healing by intra-articular bone marrow transplantation with fresh whole bone marrow cells. For anterior cruciate ligament (ACL) healing, fresh whole bone marrow cells (BMCs) that are primarily comprised of mesenchymal stem cells (MSCs) and hematopoietic stem cells should be preferably used because the combination has significant advantages over MSCs only. The dotted arrows show the cascade of events that lead to ACL healing in general. The solid arrows show the effects of intra-articular bone marrow transplant with fresh whole BMCs. (This figure was taken from Oe et al., 2011). 


\section{CONCLUSION AND FUTURURE PROSPECTS}

Stem cell therapies use several stem cell sources such as human embryonic stem cells, MSCs, BMCs, and bone marrow mononucleated cells have been reported (Chen et al., 2013). Furthermore, transplantation of the genetical transduced stem cells by "Scleraxis," which is a transcription factor involving tendon development, have been used for effective tendon regeneration (Gulotta and Rodeo, 2011). Transplantation of MSCs that are genetically transduced with "Smad8/BMP2," which is induced tendon formation and blocked differentiation of these cells into cartilage and bone tissues, has been reported to induce accelerated recovery of torn Achilles tendon (Pelled et al., 2012).

Few clinical trials have been performed using stem cells transplantations for treating tendon and ligament injuries in humans. Ahmad et al have reviewed 5 clinical studies that used stem cell therapy for treating tendon injuries and concluded that stem cells can have positive effect on tendon healing (Ahmad et al., 2012). In this review, we have reviewed the various processes that influence tissue repair by BMCT, which consist of both MSC and HSCs. The cells and processes involved in tendon healing are as follows: (1) fibroblasts that differentiate from MSCs secrete various growth factors and synthesize type-I collagen, (2) hematolymphoid cells that differentiate from HSCs secrete important growth factors and cytokines for extrinsic healing, and (3) microenvironments such as vascularization are improved in the damaged portion for tendon and ligament healing. Overall, BMCT may be more convenient and easily obtainable than cultured MSCs and can influence tendon and ligament repair though various healing processes.

\section{ACKNOWLEDGMENTS}

I would like to thank Prof. Susumu Ikehara, MD, PhD, Department of Stem Cell Disorder, Kansai Medical University, Osaka, Japan, for providing useful suggestions for this manuscript. I would also like to thank Dr. Naofumi Okamoto, MD, $\mathrm{PhD}$, and Dr. Kenichi Oe, $\mathrm{MD}, \mathrm{PhD}$, for helping me with manuscript preparation.

\section{REFERENCES}

Agung, M., Ochi, M., Yanada, S., Adachi, N., Izuta, Y., Yamasaki, T., et al. (2006). Mobilization of bone marrow-derived mesenchymal stem cells into the injured tissues after intraarticular injection and their contribution to tissue regeneration. Knee Surg. Sports Traumatol. Arthrosc. 14, 1307-1314. doi: 10.1007/s00167-006-012-8

Ahmad, Z., Wardale, J., Brooks, R., Henson, F., Noorani, A., and Rushton, N. (2012). Exploring the application of stem cells in tendon repair and regeneration. Arthroscopy 28, 1018-1029. doi: 10.1016/j.arthro.2011.12.009

Anitua, E., Andía, I., Sanchez, M., Azofra, J., del Mar Zalduendo, M., de la Fuente, M., et al. (2005). Autologous preparations rich in growth factors promote proliferation and induce VEGF and HGF production by human tendon cells in culture. J. Orthop. Res. 23, 281-286. doi: 10.1016/j.orthres.2004.08.015

Baylink, D. J., Finkelman, R. D., and Mohan, S. (1993). Growth factors to stimulate bone formation. J. Bone Miner. Res. 8, S565-S572. doi: 10.1002/jbmr.5650081326

Caplan, A. I. (2009). Why are MSCs therapeutic? New data: new insight. J. Pathol. 217, 318-324. doi: 10.1002/path.2469

Chen, H. S., Chen, Y. L., Harn, H. J., Lin, J. S., and Lin, S. Z. (2013). Stem cell therapy for tendon injury. Cell Transplant. 22, 677-684. doi: 10.3727/096368912X655118

Chong, A. K. S., Ang, A. D., Goh, J. C. H., Hui, J. H. P., Lim, A. Y. T., Lee, E. H., et al. (2007). Bone marrow-derived mesenchymal stem cells influence early tendon-healing in a rabbit Achilles tendon model. J. Bone Joint Surg. Am. 89, 74-81. doi: 10.2106/JBJS.E.01396

Deie, M., Ochi, M., and Ikuta, Y. (1995). High intrinsic healing potential of human anterior cruciate ligament. Acta Orthop. Scand. 66, 28-32. doi: $10.3109 / 17453679508994634$

Eriksen, H. A., Pajala, A., Leppilahti, J., and Risteli, J. (2002). Increased content of type III collagen at the rupture site of human Achilles tendon. J. Orthop. Res. 20, 1352-1357. doi: 10.1016/s07360266(02)00064-5

Ferreira, E., Porter, R. M., Wehling, N., O'Sullivan, R. P., Liu, F., Boskey, A., et al. (2013). Inflammatory cytokines induce a unique mineralizing phenotype in mesenchymal stem cells derived from human bone marrow. J. Biol. Chem. 288, 29494-29505. doi: 10.1074/jbc.M113.471268

Fu, S. C., Wong, Y. P., Cheuk, Y. C., Lee, K. M., and Chan, K. M. (2005). TGF- $\beta 1$ reverses the effects of matrix anchorage on the gene expression of decorin and procollagen type I in tendon fibroblasts. Clin. Orthop. Relat. Res. 431, 226-232. doi: 10.1097/01.blo.0000145887.48534.6f

Gulotta, L. V., and Rodeo, S. A. (2011). Emerging ideas: evaluation of stem cells genetically modified with scleraxis to improve rotator cuff healing. Clin. Orthop. Relat. Res. 469, 2977-2980. doi: 10.1007/s11999-010-1727-4

Halper, J. (2014). Advances in the use of growth factors for treatment of disorders of soft tissues. $A d v$. Exp. Med. Biol. 802, 59-76. doi: 10.1007/978-94007-7893-1_5

Hou, Y., Mao, Z., Wei, X., Lin, L., Chen, L., Wang, H., et al. (2009). Effects of transforming growth factor- $\beta 1$ and vascular endothelial growth factor 165 gene transfer on Achilles tendon healing. Matrix Biol. 28, 324-335. doi: 10.1016/j.matbio.2009.04.007

Ju, Y. J., Muneta, T., Yoshimura, H., Koga, H., and Sekiya, I. (2008). Synovial mesenchymal stem cells accelerate early remodeling of tendonbone healing. Cell Tissue Res. 332, 469-478. doi: 10.1007/s00441-008-0610-z

Kanaya, A., Deie, M., Adachi, N., Nishimori, M., Yanada, S., and Ochi, M. (2007). Intraarticular injection of mesenchymal stromal cells in partially torn anterior cruciate ligaments in a rat model. Arthroscopy 23, 610-617. doi: 10.1016/J.arthro.2007.01.013

Kiapour, A. M., and Murray, M. M. (2014). Basic science of anterior cruciate ligament injury and repair. Bone Joint Res. 3, 20-31. doi: 10.1302/20463758.32.2000241

Koga, H., Muneta, T., Ju, Y. J., Nagase, T., Nimura, A., Mochizuki, T., et al. (2007). Synovial stem cells are regionally specified according to local microenvironments after implantation for cartilage regeneration. Stem Cells 25, 689-696. doi: 10.1634/stemcells.2006-0281

Lee, J., Harwood, F. L., Akeson, W. H., and Amiel, D. (1998). Growth factor expression in healing rabbit medial collateral and anterior cruciate ligaments. Iowa Orthop. J. 18, 19-25.

Le Blanc, K., and Ringdén, O. (2006). Mesenchymal stem cells: properties and role in clinical bone marrow transplantation. Curr. Opin. Immunol. 18, 586-591. doi: 10.1016/j.coi.2006.07.004

Liu, S. H., Yang, R. S., al-Shaikh, R., and Lane, J. M. (1995). Collagen in tendon, ligament, and bone healing. A current review. Clin. Orthop. Relat. Res. 31, 265-278.

Marui, T., Niyibizi, C., Georgescu, H. I., Cao, M., Kavalkovich, K. W., Levine, R. E., et al. (1997). Effect of growth factors on matrix synthesis by ligament fibroblasts. J. Orthop. Res. 15, 18-23. doi: 10.1002/jor.1100150104

Mienaltowski, M. J., and Birk, D. E. (2014). Mouse models in tendon and ligament research. Adv. Exp. Med. Biol. 802, 201-230. doi: 10.1007/978-94-0077893-1_13

Molloy, T., Wang, Y., and Murrell, G. (2003). The roles of growth factors in tendon and ligament healing. Sports Med. 33, 381-394. doi: 10.2165/00007256200333050-00004

Moraes, V. Y., Lenza, M., Tamaoki, M. J., Faloppa, F., and Belloti, J. C. (2014). Platelet-rich therapies for musculoskeletal soft tissue injuries. Cochrane Database Syst. Rev. 4, 1-79. doi: 10.1002/14651858.CD010071.pub3

Oe, K., Kushida, T., Okamoto, N., Umeda, M., Nakamura, T., Ikehara, S., et al. (2011). New strategies for anterior cruciate ligament partial rupture using bone marrow transplantation in rats. Stem Cells Dev. 20, 671-679. doi: 10.1089/scd.2010.0182

Okamoto, N., Kushida, T., Oe, K., Umeda, M., Ikehara, S., and Iida, H. (2010). Treating Achilles tendon rupture in rats with bone-marrowcell transplantation therapy. J. Bone Joint Surg. Am. 92, 2776-2784. doi: 10.2106/JBJS. I.01325

Pelled, G., Snedeker, J. G., Ben-Arav, A., Rigozzi, S., Zilberman, Y., Kimelman-Bleich, N., et al. (2012). Smad8/BMP2-engineered mesenchymal stem cells 
induce accelerated recovery of the biomechanical properties of the Achilles tendon. J. Orthop. Res. 30, 1932-1939. doi: 10.1002/jor.22167

Scherping, S. C. Jr., Schmidt, C. C., Georgescu, H. I., Kwoh, C. K., Evans, C. H., and Woo, S. L. (1997). Effect of growth factors on the proliferation of ligament fibroblasts from skeletally mature rabbits. Connect. Tissue Res. 36, 1-8. doi: 10.3109/03008209709160209

Schmidt, C. C., Georgescu, H. I., Kwoh, C. K., Blomstrom, G. L., Engle, C. P., Larkin, L. A., et al. (1995). Effect of growth factors on the proliferation of fibroblasts from the medial collateral and anterior cruciate ligaments. J. Orthop. Res. 13, 184-190. doi: 10.1002/jor.1100 130206

Sporn, M. B., Roberts, A. B., Wakefield, L. M., and Assoian, R. K. (1986). Transforming growth factor- $\beta$ : biological function and chemical structure. Science 233, 532-534. doi: 10.1126/science. 3487831

Wang, X. J., Dong, Z., Zhong, X. H., Shi, R. Z., Huang, S. H., Lou, Y., et al. (2008). Transforming growth factor- $\beta 1$ enhanced vascular endothelial growth factor synthesis in mesenchymal stem cells.
Biochem. Biophys. Res. Commu. 365, 548-554. doi: 10.1016/j.bbrc.2007.11.014

Wang, X. T., Liu, P. Y., and Tang, J. B. (2005). Tendon healing in vitro: modification of tenocytes with exogenous vascular endothelial growth factor gene increases expression of transforming growth factor $\beta$ but minimally affects expression of collagen genes. J. Hand Surg. Am. 30, 222-229. doi: 10.1016/j.jhsa.2004.09.002

Wang, X., Wang, Y., Gou, W., Lu, Q., Peng, J., and Lu, S. (2013). Role of mesenchymal stem cells in bone regeneration and fracture repair: a review. Int Orthop. Dec. 37, 2491-2498. doi: 10.1007/s00264013-2059-2

Zantop, T., Gilbert, T. W., Yoder, M. C., and Badylak, S. F. (2006). Extracellular matrix scaffolds are repopulated by bone marrow-derived cells in a mouse model of Achilles tendon reconstruction. J. Orthop. Res. 24, 1299-1309. doi: 10.1002/jor.20071

Zhang, F., Liu, H., Stile, F., Lei, M. P., Pang, Y., Oswald, T. M., et al. (2003). Effect of vascular endothelial growth factor on rat Achilles tendon healing. Plast. Reconstr. Surg. 112, 1613-1619. doi: 10.1022/jor.20071
Conflict of Interest Statement: The authors declare that the research was conducted in the absence of any commercial or financial relationships that could be construed as a potential conflict of interest.

Received: 12 May 2014; accepted: 18 June 2014; published online: 15 July 2014.

Citation: Kushida T and Iida $H$ (2014) Bone marrow cell transplantation efficiently repairs tendon and ligament injuries. Front. Cell Dev. Biol. 2:27. doi: 10.3389/ fcell.2014.00027

This article was submitted to Stem Cell Treatments, a section of the journal Frontiers in Cell and Developmental Biology.

Copyright (c) 2014 Kushida and Iida. This is an open-access article distributed under the terms of the Creative Commons Attribution License (CC BY). The use, distribution or reproduction in other forums is permitted, provided the original author(s) or licensor are credited and that the original publication in this journal is cited, in accordance with accepted academic practice. No use, distribution or reproduction is permitted which does not comply with these terms. 